\title{
Individual and family characteristics associated with BRCAI/2 genetic testing in high-risk families
}

\author{
Maria C. Katapodi'*, Laurel L. Northouse', Kara J. Milliron², Guipeng Liu' and Sofia D. Merajver² \\ 'University of Michigan School of Nursing, Ann Arbor, MI USA \\ ${ }^{2}$ University of Michigan Breast and Ovarian Cancer Risk Evaluation Program, Ann Arbor, MI USA
}

* Correspondence to:

University of Michigan School of

Nursing, 400 North Ingalls

Building, Room 2158, Ann Arbor

MI 48/09, USA. E-mail:

mkatapo@umich.edu

\begin{abstract}
Background: Little is known about family members' interrelated decisions to seek genetic testing for breast cancer susceptibility.

Methods: The specific aims of this cross-sectional, descriptive, cohort study were (i) to examine whether individual and family characteristics have a direct effect on women's decisions to use genetic testing for hereditary susceptibility to breast cancer and (ii) to explore whether family characteristics moderate the relationships between individual characteristics and the decision to use genetic testing. Participants were women ( $>18$ years old) who (i) received genetic testing for hereditary breast cancer and who agreed to invite one of their female relatives into the study and (ii) female relatives who had NOT obtained genetic testing and were identified by pedigree analysis as having $>10 \%$ chances of hereditary susceptibility to breast cancer.

Results: The final sample consisted of 168 English-speaking, family dyads who completed selfadministered, mailed surveys with validated instruments. Multivariate conditional logistic regression analyses showed that the proposed model explained $62 \%$ of the variance in genetic testing. The factors most significantly associated with genetic testing were having a personal history of cancer; perceiving genetic testing to have more benefits than barriers; having greater family hardiness; and perceiving fewer negative consequences associated with a breast cancer diagnosis. No significant interaction effects were observed.

Conclusions: Findings suggest that both individual and family characteristics are associated with the decision to obtain genetic testing for hereditary breast cancer; hence, there is a need for interventions that foster a supportive family environment for patients and their high-risk relatives. Copyright $($ ) 2012 John Wiley \& Sons, Ltd.
\end{abstract}

Received: 9 March 2012 Revised: 26 June 2012 Accepted: 28 June 2012 of $B R C A 1 / 2$ testing have been reported to be between $26 \%$ and $80 \%[15,16]$. Thus, the challenge is to identify factors that are associated with this decision. Little is known about family members' interrelated decisions for $B R C A 1 / 2$ testing. This study used a theoretically guided approach to examine family characteristics that influence decisions for genetic testing and interactions between individual and family characteristics.

\section{Theoretical framework and literature review}

The investigation of how individual and family characteristics influence decisions about genetic testing was guided by the integration of three theories: stress and coping [17], decision making [18], and family systems in genetic illness [19] (Figure 1). According to the theory of stress and coping, a woman's initial response to learning about her hereditary cancer risk would be to appraise the level of threat associated with this information. This initial appraisal is followed by secondary appraisals of the level of psychological distress caused by this threat and the availability of coping resources. These secondary appraisals most likely include an assessment of the benefits and barriers of genetic testing. In cases of hereditary breast cancer, the decision to use genetic testing has implications for the whole family. Multiple family members are likely to be involved, directly or indirectly, in assessments of benefits and barriers of genetic testing. Thus, input guided by family relationships and family communication 


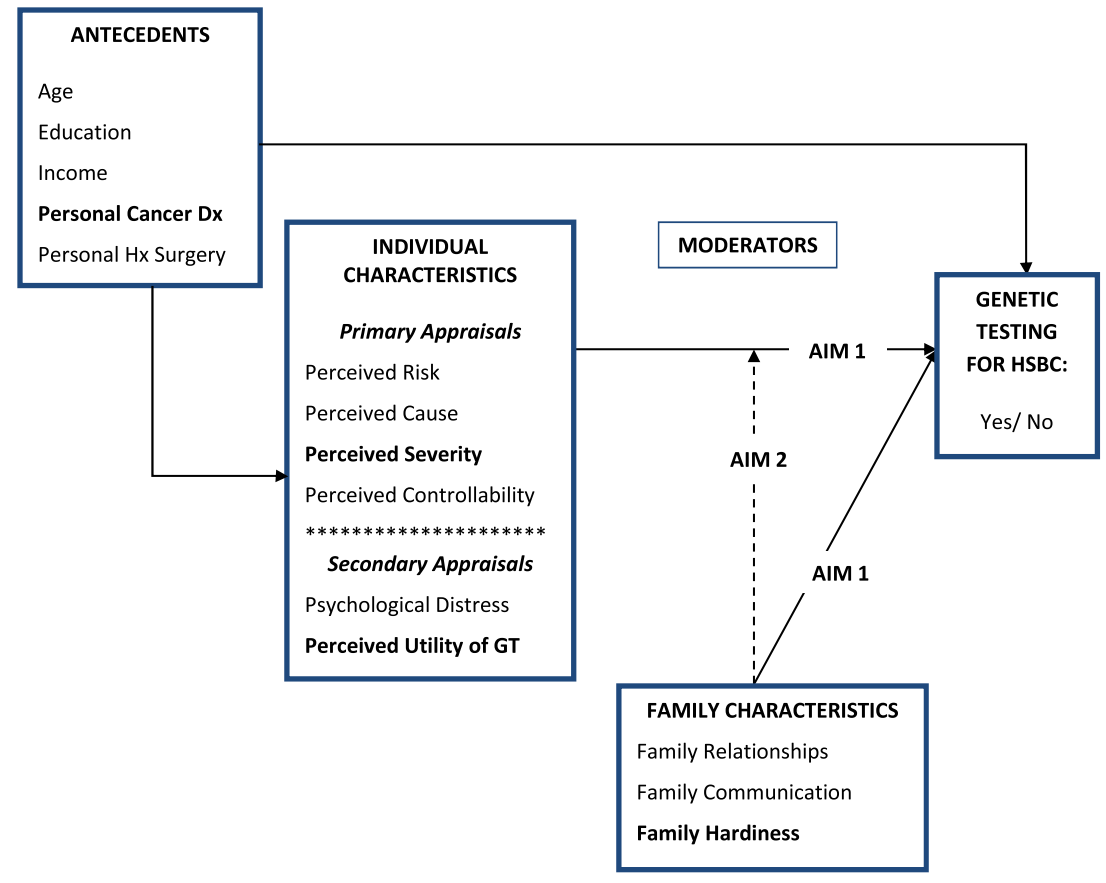

* Variables in Bold were significant predictors of genetic testing for hereditary susceptibility in breast

cancer in the multivariate analysis

Figure I. Theoretical framework

determines the overall attractiveness of genetic testing and shapes this decision-making process.

There is empirical support for the strength of some of the proposed relationships. High perceived risk of developing cancer has been associated with greater frequency of genetic testing [20,21]. Incomplete or inaccurate knowledge of breast cancer genetics has been associated with low rates of testing [22]. Although high psychological distress has been associated with increased use of genetic testing [23], it has also been linked to decreased ability to understand genetic information and to make informed decisions $[21,24]$. Genetic testing is less likely when perceived barriers (e.g., lack of access to quality care or concern about abuse of test results) outweigh perceived benefits [25-27].

There is less evidence about the role that the family environment plays in decisions about genetic testing. Most studies examined the role of family environment in disclosure of genetic test results. Family communication affects what genetic information will be shared and with whom [28]. Women are more likely to communicate genetic test results with close relatives, such as their sisters, and with younger family members [29-31]. Individuals without identified mutations disclose genetic test results to fewer relatives compared with mutation carriers [30-32]. Genetic testing is more likely to be discussed among families with higher cohesiveness and lower family conflict [33]. Family members often disagree as to whether genetic testing is a personal or a family decision, which may lead to conflict about disclosure of test results $[26,34,35]$. However, to date few studies have examined the relationship between family characteristics and the actual decision to use genetic testing. It has been suggested that an unsupportive family environment has been associated with low rates of testing [36-40]. However, more information is necessary in order to provide decision support to families who harbor cancerpredisposing mutations.

The specific aims of the study were (i) to examine whether individual and family characteristics have a direct effect on women's decisions to use genetic testing for hereditary breast cancer and (ii) to explore whether family characteristics moderate the relationships between individual characteristics and the decision to use genetic testing (Figure 1).

\section{Methods}

\section{Design, setting, eligibility criteria, and recruitment procedures}

Participants for this cross-sectional, descriptive, cohort study were obtained from two genetics clinics at a large comprehensive cancer center. The two clinics provide risk assessment, genetic counseling, and testing for mutations associated with different hereditary cancers. Individuals attending the clinics are either referred by a healthcare provider or are self-referred. If the chance of carrying a germline mutation is greater than $10 \%$, genetic testing is recommended; otherwise, it is discouraged but not denied.

The study recruited two cohorts: women who had received genetic testing for $B R C A 1 / 2$ mutations (probands) and one of their female relatives who did NOT have genetic testing. All participants were female, English-speaking, and age 18 years or older. The study focused on women with hereditary susceptibility to breast cancer because women are more likely to communicate about breast cancer genetics with other women in their family [29].

Probands were eligible to participate if their test result was positive or indeterminate/uninformative for $B R C A 1 / 2$ mutation, and if they agreed to invite one of their high-risk 
relatives into the study. Relatives were eligible if pedigree analysis revealed that they had a $>10 \%$ chance of hereditary susceptibility to breast cancer, but they did NOT have genetic testing. Pedigree analysis is based on the degree of relatedness between the proband and her relatives and the results of genetic testing. Because $B R C A 1 / 2$ mutations are inherited with an autosomal-dominant pattern, in cases of an identified mutation first-degree relatives have $50 \%$ chance of carrying the same mutation, second-degree relatives have $25 \%$ chance, and third-degree relatives have $12.5 \%$ chance. In cases of an indeterminate/uninformative test result, pedigree analysis takes into consideration family size and the family side hypothesized to harbor a deleterious mutation. An 'indeterminate/uninformative' test result means (i) a person has a negative test result when family history is highly suggestive of hereditary breast/ovarian cancer syndrome, or (ii) an unaffected individual has a negative test result, and there is not an affected family member to test. In such cases, it is recommended to test multiple family members because the breast cancer seen in the family might be a phenocopy (a change in phenotype arising from environmental agent that mimics the effect of a mutation).

The study protocol was approved by the Institutional Review Board. A genetic counselor reviewed the files of women who had genetic testing for hereditary breast cancer to identify eligible probands and potentially eligible relatives. Probands who had at least one eligible relative were sent an invitation letter and an informed consent document. The invitation letter was tailored for each proband and identified her potentially eligible female relatives (e.g., sister, maternal/paternal aunt, niece, maternal/ paternal first cousin). The letter explained that each proband could invite the relative of her choice from those included in the list but only if the relative had not been tested. The invitation letter was followed by a phone call by the genetic counselor to explain the study and to ascertain the relatives' eligibility. A self-administered survey was mailed to probands agreeing to take part in the study, along with an invitation letter, consent form, and a similar self-administered survey for her relative. The relatives' name and identifying information was not provided to research staff until she consented to be in the study. Each participant was compensated $\$ 20$ for her time.

\section{Instruments}

Demographics, personal history of cancer, and surgical history were based on self-report. Table 1 provides information about the validity and reliability of the instruments used to measure individual and family characteristics. Perceived risk was assessed by asking participants to rate their chances of developing breast cancer compared with other women in their family. This item was developed on the assumption that family members are part of complex networks in which risk appraisals are formulated and evaluated at a collective familial level [41]. Perceived cause was assessed with two scales that evaluate knowledge of genetic inheritance and knowledge of breast cancer risk factors [42,43];

Table I. Characteristics of instruments

\begin{tabular}{|c|c|c|c|c|}
\hline Construct & Concept & Instrument & $\begin{array}{l}\text { Cronbach's } \\
\text { alpha }\end{array}$ & $\begin{array}{l}\text { Test- } \\
\text { retest } \\
\text { reliability }\end{array}$ \\
\hline \multirow[t]{4}{*}{$\begin{array}{l}\text { Individual } \\
\text { characteristics }\end{array}$} & $\begin{array}{l}\text { Perceived risk } \\
\text { breast cancer }\end{array}$ & $\begin{array}{l}\text { 'Rate your chances of developing breast cancer } \\
\text { compared with other women in your family'. } \\
\text { Likert type; range I 'a lot lower' to } 7 \text { 'a lot higher' } \\
\text { Developed for the study }\end{array}$ & - & - \\
\hline & Perceived cause & $\begin{array}{l}\text { Knowledge of modes of gene inheritance: } \\
\quad 15 \text { multiple choice items about breast cancer genetics. } \\
\text { Previously tested with high-risk women [43] }\end{array}$ & 0.82 & - \\
\hline & & $\begin{array}{l}\text { Knowledge of HBOC risk factors: } 19 \text { items; answers } \\
\text { 'yes' 'no' 'do not know'. Earlier version used with } \\
\text { a sample including I5\% of high-risk women [42] }\end{array}$ & 0.89 & - \\
\hline & Perceived severity & $\begin{array}{l}\text { Subscale of IPQ-R; Likert type; range I 'strongly } \\
\text { disagree' to } 7 \text { 'strongly agree'. Used with } \\
\text { breast cancer patients and healthy controls [53] }\end{array}$ & 0.78 & $0.48-0.88$ \\
\hline $\begin{array}{l}\text { Psychological } \\
\text { distress }\end{array}$ & $\begin{array}{l}\text { Psychological } \\
\text { distress breast } \\
\text { and ovarian cancer }\end{array}$ & $\begin{array}{l}\text { 'How often you were worried' and 'How emotionally } \\
\text { upset or distressed you had been' about the possibility } \\
\text { of developing breast cancer; range from I 'never/not } \\
\text { at all' to I0 'all the time/a great deal'. Used with a } \\
\text { sample containing I5\% of high-risk women [45] }\end{array}$ & 0.90 & - \\
\hline $\begin{array}{l}\text { Perceived utility } \\
\text { of genetic testing }\end{array}$ & $\begin{array}{l}\text { Perceived benefits- } \\
\text { perceived barriers }\end{array}$ & $\begin{array}{l}\text { Perceived benefits; } 8 \text { Likert-type items; range I 'strongly } \\
\text { disagree' to } 7 \text { 'strongly agree'. Perceived barriers; } \\
7 \text { Likert-type items; range I 'strongly disagree' to } 7 \text { 'strongly } \\
\text { agree'. Used with women undergoing genetic testing [25] }\end{array}$ & 0.80 and $0.7 \mid$ & - \\
\hline \multirow[t]{3}{*}{ Family characteristics } & Family relationships & $\begin{array}{c}\text { Family Relationships Inventory; } 27 \text { Likert-type items; range I } \\
\text { 'never' to } 7 \text { 'always'. Used with high-risk families [46] }\end{array}$ & 0.79 & 0.75 \\
\hline & Family communication & $\begin{array}{l}\text { Family Problem Solving and Communication Index; } \\
\qquad 10 \text { Likert-type items; range I 'never' to } 7 \text { 'always' [47] }\end{array}$ & 0.89 & 0.86 \\
\hline & Family hardiness & $\begin{array}{l}\text { Family Hardiness Scale; } 20 \text { Likert-type items; range I 'never' } \\
\text { to } 7 \text { 'always'[48] }\end{array}$ & 0.92 & $0.78-0.86$ \\
\hline
\end{tabular}


higher scores indicated greater knowledge (scores were summed). Perceived severity (i.e., negative consequences of breast cancer) and perceived controllability were measured with subscales of the Revised-Illness Perceptions Questionnaire [44]. Psychological distress was measured with previously validated items [45]. A composite score from two subscales assessing perceived benefits and barriers of genetic testing measured perceived utility of genetic testing [25]. Family relationship was assessed with the Family Relationships Inventory [46] that evaluates family cohesion, expressiveness in communication, and conflict resolution. The Family Problem Solving and Communication Index [47], used to assess family communication, measures incendiary and affirming family communication, and how families manage tension and acquire functioning, adjustment, and adaptation. Family hardiness measures cohesion and ability to cope with adverse events [48].

\section{Data analyses}

Missing data were assessed with Proc MI in SAS version 9 (SAS Institute Inc. NC, USA) and missing values for psychosocial instruments were imputed [49] (SAS MI procedure). Descriptive statistics were used to describe demographic characteristics and survey responses. Conditional logistic regression analysis, which accounted for the matched observations (proband-relative dyads) and for the dichotomous primary outcome (genetic testing: yes/no) were conducted in SAS version 9. Relationships between predictive variables and the outcome were tested in a three-step process: (i) variables were initially tested in univariate conditional logistic regressions; (ii) those that were significantly associated with genetic testing were tested together in a multivariate model; and (iii) moderation analyses examined if family characteristics (i.e., relationships, communication, and hardiness) moderated the effect of individual characteristics on the decision to have genetic testing. Power analysis indicated that with alpha of 0.05 , a sample of 147 matched proband-relative dyads (pairs) would provide $80 \%$ power to detect moderate correlations among the predictive variables and the outcome $\left(R^{2}=0.13\right)$.

\section{Results}

The project recruited an overall sample of $N=372$ participants including 200 probands and 172 of their female relatives. Thirty-two probands withdrew from the study because all high-risk relatives have been tested $(n=6)$; eligible relatives did not agree to participate $(n=12)$; they did not have enough time $(n=3)$; they were too upset, distressed, worried $(n=7)$; or for no reason $(n=4)$. The final sample in this analysis includes 168 matched probandrelative dyads $(N=336$ participants), where both the proband and the relative completed and returned their survey.

Demographics of the sample included the following: Caucasian (95\%), married or had a life partner $(73 \%)$, employed full-time or part-time $(66 \%)$, had health insurance (96\%), and income $\geq \$ 61,000(61 \%)$. Probands were on average 30 months post-genetic testing (range 2-58). Table 2 presents additional demographic and health information for probands and relatives. Probands were older and more educated than relatives, but these differences were not significant. Most probands $(86 \%)$ had a personal history of cancer compared with $21 \%$ of relatives $(p<0.05)$.

Among the 168 matched dyads, $n=23$ probands (14\%) tested positive for a BRCA1/2 mutation (true positives). The remaining $n=145$ probands who received a negative test result were classified as 'indeterminate/uninformative'. The 168 high-risk relatives did not have genetic testing and were of unknown mutation status. Almost half of the relatives that participated in the study $(52 \%)$ were firstdegree relatives ( $n=45$ sisters, $n=31$ daughters, $n=11$ mothers). Approximately $18 \%$ were second-degree relatives ( $n=14$ aunts, $n=16$ nieces) and approximately $11 \%$ were third-degree relatives ( $n=18$ first cousins). For 33 dyads in the study (20\%), the degree of relatedness could not be determined from the data provided.

Table 2. Characteristics of the two cohorts

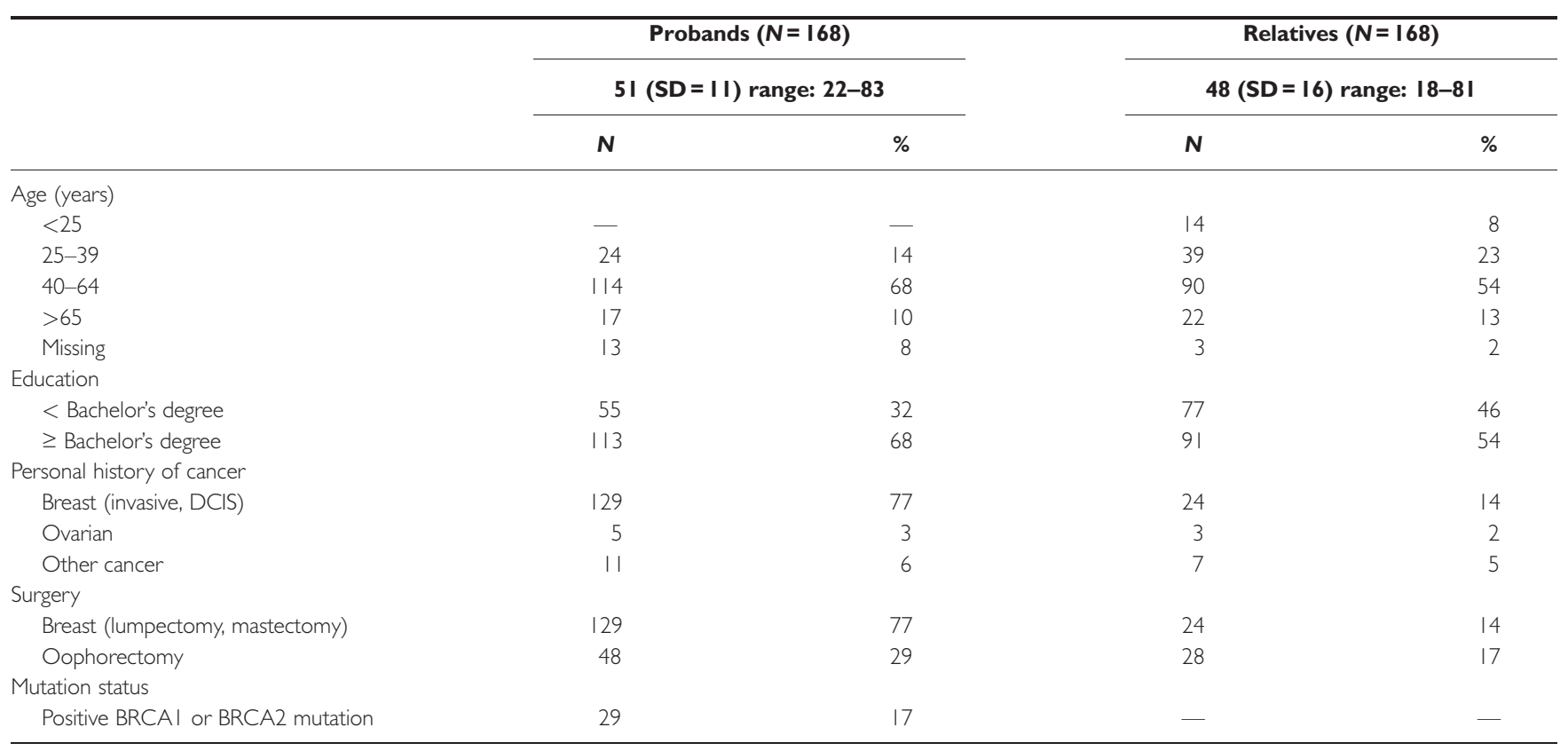

DCIS, ductal cell carcinoma in situ; BRCAI and BRCA2, Breast Cancer I and Breast Cancer 2. 


\section{Univariate analyses}

Variables that were positively associated with genetic testing in the univariate conditional regression analyses were education $(\mathrm{OR}=1.23, p=0.01)$; personal history of cancer $(\mathrm{OR}=5.12, p<0.0001)$; perceived risk $(\mathrm{OR}=1.45$, $p<0.0001)$; perceived cause $(\mathrm{OR}=1.65, p<0.0001)$; psychological distress $(\mathrm{OR}=1.12, p=0.03)$; perceived utility of genetic testing $(\mathrm{OR}=2.30, p<0.0001)$; and family hardiness $(\mathrm{OR}=1.36, p=0.02)$. Perceived severity $(\mathrm{OR}=$ $0.49, p<0.0001)$ and perceived controllability $(\mathrm{OR}=0.72$, $p=0.04)$ were negatively associated with genetic testing (Table 3).

\section{Multivariate analysis}

Variables associated with genetic testing in the univariate analyses were tested with a multivariate logistic regression model (Table 4). The model explained $62 \%$ of the variance in genetic testing (max-rescaled R-square $=0.62$ ). Having a personal history of cancer was the most significant variable associated with genetic testing ( $\mathrm{OR}=4.76, p=0.009)$; after holding other variables fixed, there was a $376 \%$ increase in the odds of genetic testing after having a cancer diagnosis. Perceived utility of genetic testing was the second most significant variable associated with genetic testing $(\mathrm{OR}=1.97, p=0.009)$; after holding other variables fixed, there was a $97 \%$ increase in the odds of genetic testing for one-unit increase in perceived utility. Family hardiness was the third most significant variable associated with genetic testing $(\mathrm{OR}=1.29, p=0.04)$; after holding other variables fixed, there was a $29 \%$ increase in the odds of genetic testing for one-unit increase in the family hardiness index. Finally, perceived severity was the fourth variable significantly associated with genetic testing $(\mathrm{OR}=0.52, p=0.02)$; after holding other variables fixed, there was a $52 \%$ decrease in the odds of genetic testing for one-unit increase in perceived severity of breast cancer.

\section{Interactions between individual and family characteristics}

Data were analyzed for possible interactions between individual and family characteristics (Figure 1, Aim 2). There were no significant interactions. Only the term 'family communication * perceived cause' approached statistical significance $(\mathrm{OR}=1.22, p=0.055)$.

\section{Discussion}

This study examined individual and familial characteristics associated with genetic testing for hereditary susceptibility to breast cancer in two related cohorts of women: probands who had genetic testing and one of their high-risk female relatives who had not been tested. Probands had received genetic counseling and most had a personal cancer diagnosis. In contrast, their relatives did not have genetic testing and fewer had a personal cancer history. These differences between the two cohorts are taken into account when interpreting study findings.

Consistent with other studies [29-31], probands were more likely to select their first-degree relatives and mostly their sisters to invite in the study. Relatives were on

Table 3. Univariate conditional logistic regression analyses

\begin{tabular}{|c|c|c|c|c|}
\hline Predictor & Odds ratio & Estimate & Wald chi-square & p-value \\
\hline Age & 0.93 & 0.07 & 0.09 & 0.77 \\
\hline Income & 1.35 & 0.30 & 1.61 & 0.21 \\
\hline Education & 1.23 & 0.20 & 6.04 & 0.01 \\
\hline Personal history of cancer & 5.12 & 1.63 & 42.82 & $<0.001$ \\
\hline Personal history of surgery & 1.44 & 0.37 & 1.94 & 0.16 \\
\hline Perceived risk $\mathrm{HBOC}$ & 1.45 & 0.37 & $|5.9|$ & $<0.001$ \\
\hline Perceived cause HBOC & 1.65 & 0.53 & 29.63 & $<0.001$ \\
\hline Perceived severity HBOC & 0.49 & -1.02 & 21.39 & $<0.001$ \\
\hline Perceived controllability & 0.72 & -0.33 & 3.74 & 0.05 \\
\hline Psychological distress HBOC & 1.12 & 0.06 & 2.76 & 0.03 \\
\hline Perceived utility of genetic testing & 2.30 & 1.39 & 31.05 & $<0.001$ \\
\hline Family relationships & 1.52 & 0.42 & 1.02 & 0.31 \\
\hline Family problem solving communication & 1.15 & 1.14 & 0.44 & 0.51 \\
\hline Family Hardiness Index & 1.36 & 1.03 & 5.61 & 0.02 \\
\hline
\end{tabular}

Bold emphasis is used to identify statistically significant relationships.

$\mathrm{HBOC}$, hereditary breast and ovarian cancer.

Table 4. Multivariate conditional logistic regression analysis

\begin{tabular}{|c|c|c|c|c|}
\hline Predictor & Odds ratio & Estimate & Wald chi-square & $p$-value \\
\hline Education & 1.38 & 0.32 & 0.44 & 0.51 \\
\hline Personal history of cancer & 4.76 & 3.74 & 6.90 & 0.01 \\
\hline Perceived risk $\mathrm{HBOC}$ & 1.29 & 0.25 & 0.47 & 0.49 \\
\hline Perceived cause $\mathrm{HBOC}$ & 2.13 & 0.75 & 2.76 & 0.10 \\
\hline Perceived severity HBOC & 0.52 & -1.68 & 4.05 & 0.02 \\
\hline Perceived controllability & 0.74 & -0.30 & 0.15 & 0.70 \\
\hline Psychological distress HBOC & 1.14 & 0.42 & 1.02 & 0.15 \\
\hline Perceived utility of genetic testing & 1.97 & 3.32 & 6.83 & 0.01 \\
\hline Family Hardiness Index & 1.29 & 3.22 & 3.60 & 0.04 \\
\hline
\end{tabular}

$\mathrm{HBOC}$, hereditary breast and ovarian cancer. 
average younger than probands, which is consistent with previous reports that younger age of the relative is a predictor of communication of genetic information [29]. Communication of test results occurs primarily among nuclear families and first-degree relatives [22,28,37]. This means that more distant family members, such as seconddegree and third-degree relatives, who may also benefit from the genetic information, are often left out of this communication process. This has significant clinical and ethical implications and points to an area for further intervention.

The present study focused on examining individual and family predictors of $B R C A 1 / 2$ testing. Variables most significantly associated with genetic testing were having a personal cancer diagnosis and perceiving genetic testing to have more benefits than barriers. These findings are consistent with other studies reporting that most women who present for genetic testing already have a personal cancer diagnosis $[21,50]$ and believe that genetic testing has more benefits than barriers [25]. Women already affected by breast cancer are the best candidates for genetic testing compared with other family members. Thus, it is not surprising that most probands in the study had a personal cancer diagnosis. However, this finding can also be partially interpreted as a failure of the healthcare system to screen and identify high-risk individuals when they are still unaffected by cancer. This could significantly reduce morbidity from hereditary breast cancer and associated healthcare costs. Findings highlight the need for new strategies that increase early identification of highrisk women and appropriate referrals to genetic counseling.

Genetic testing was positively associated with higher family hardiness, which is a new finding. Family hardiness is a measure of family resiliency which can be defined as the family's cohesion and ability to overcome adverse events. We examined whether probands reported higher family hardiness compared with relatives, but the difference was not statistically significant (data not shown). It is possible that probands, who reported greater family hardiness, had also developed stronger family networks that increased their coping resources for dealing with cancer diagnosis and the stress associated with genetic testing. The retrospective and cross-sectional design of this study does not allow causal inferences between family hardiness and genetic testing. A prospective cohort study is more appropriate to further examine this association.

There was a negative association between genetic testing and perceiving more negative consequences of breast cancer. It is not uncommon for cancer-free women, like most of the relatives in this study, to overestimate the negative consequences of breast cancer [51]. Genetic counseling offered probands accurate information about their cancer risk, the genetics of cancer, and options for risk management. In contrast, relatives most likely did not have genetic counseling and were informed about their potential susceptibility to the disease by probands. This assumption is based on a study by Lerman et al. [52], which reported that women often commit to a decision about genetic testing before they participate in counseling. The majority of women who participate in counseling opt to be tested, whereas those who decide not to be tested do not avail themselves of genetic counseling [52]. Among relatives, the lack of knowledge regarding cancer genetics and risk management options may have contributed toward overestimation of the negative consequences of the disease. This may lead to more avoidant coping and less interest in obtaining genetic testing.

One significant contribution of the study is the integration of stress and coping theory with decision-making theory and the family systems in genetic illness theory. Stress and coping theory has been adopted extensively in the area of psychosocial research. A meta-analysis of 45 studies reported that many of the theory constructs have been supported across different illnesses [53]. However, stress and coping theory does not include family characteristics and cannot fully explain the interrelated decisions of high-risk family members about use of genetic testing. The theoretical integration that guided this study provides a comprehensive way of examining the individual and familial context of genetic testing for hereditary susceptibility to breast cancer.

Family communication may have a wide range of influences on interrelated decisions for genetic testing. Empirical evidence suggests that family cohesion and openness may facilitate communication of genetic test results [29,50]. It makes intuitive sense that members of families with open communication would be more informed about the genetics of breast cancer, whereas members of families with less open communication will have inadequate and inaccurate information and would be less likely to have genetic testing. In this study, the moderation effect between family communication and perceived cause approached statistical significance. Although power calculations indicated that the sample was adequate to answer the primary aim, it is possible that the study was underpowered to detect a moderation effect. Often moderation effects are much smaller than the main effect, so a much larger sample may be needed. Future studies should further investigate this topic.

\section{Limitations}

First, personal history of cancer, surgical history, and lack of genetic testing in relatives were based on self-reports and may not be accurate. Limited participation of non-Caucasian women and women diagnosed with ovarian cancer decreases generalizability of findings. The decision-making process about genetic testing is a dynamic phenomenon, evolving over time, with input from medical diagnoses, genetic information, and the family environment. The cross-sectional and retrospective design of this study limits our understanding of the effects of individual and family characteristics when the actual decision about genetic testing was made. Additional information, including whether probands communicated test results to relatives, how long after genetic testing, and whether there was ongoing discussion about the relative being tested was not available. This information would have helped us better understand the intra-familial decision-making process. Finally, because of federal regulations regarding protection of identifiable health information, the research team could not recruit eligible relatives directly. Rather, probands recruited relatives in the study. On one hand, this affected variance in family relationships and family communication because probands likely chose to recruit the relative they feel close to or have higher stakes in her testing. On the other 
hand, this recruitment method targets women who have higher-than-average breast cancer risk because of their strong family history. Despite its limitations, this recruitment method provides access to a community-dwelling sample of women who could benefit from an early detection intervention. The large sample of the two related cohorts of women and the comprehensive examination of individual and family characteristics are also significant contributions of the study.

\section{Clinical implications}

This study provides evidence for the individual and family characteristics that influence the decision to use genetic testing for hereditary breast cancer. Given the rapid discovery of cancer susceptibility genes, there is an increased need for empirically validated methods that facilitate family care for families with hereditary cancer syndromes. Genetic information is unique, because it is both private to the individual and also needs to be shared with family members. Given the ramifications of genetic information for family members, a shift in healthcare toward a family-based model is imperative.

The need to include family members in the decisionmaking process about genetic testing has been recognized [54]. Decisional aids and educational tools about hereditary cancer and genetic testing should address the needs of both the proband and the family members involved in this process. Although interventions to increase family participation during genetic counseling exist $[57,58]$, there is great variability in family involvement during this process and potentially great variability in family care among different clinical settings. Thus, identifying and intervening with patients and families at greatest need for psychosocial care when deciding about BRCA1/2 testing will enhance standards of care. Findings from this study point to the family environment as an important new area for clinical intervention during decision making about genetic testing. Family relations are pre-existing structures that may function as means of social support and enhance quality decision making about genetic testing. Systematic assessment of the family network and the coping resources at the familial level is the first step forward. Family-based interventions that provide comprehensive communication, coping, and decisional support about genetic testing are needed.

\section{Acknowledgement}

Data collection was funded by the Oncology Nursing Foundation, 2007 Breast Cancer Research Award. The first author is funded by the Robert Wood Johnson Foundation - Nurse Faculty Scholars program.

\section{Conflict of interest}

None declared.

\section{References}

1. Foulkes WD. Inherited susceptibility to common cancers. $N$ Engl J Med 2008;359(20): 2143-2153.

2. Ripperger T, Gadzicki D, Meindl A, Schlegelberger B. Breast cancer susceptibility: current knowledge and implications for geneticcounselling. Eur J Hum Genet 2009;17(6): 722-731.

3. Futreal PA, Liu Q, Shattuck-Eidens D, et al. BRCA1 mutations in primary breast and ovarian carcinomas. Science 1994;266(5182):120-122.

4. Miki Y, Swensen J, Shattuck-Eidens D, et al. A strong candidate for the breast and ovarian cancer susceptibility gene BRCA1. Science 1994;266:66-71.

5. Wooster R, Bignell G, Lancaster J, et al. Identification of the breast cancer susceptibility gene BRCA2. Nature 1995;378:789-792.

6. King MC, Marcs JH, Mandell JB, et al. Breast and ovarian cancer due to inherited mutations in BRCA1 and BRCA2. Science 2003; 302(5645):643-646.

7. Chen S, Iversen ES, Friebel T, et al. Characterization of BRCA1 and BRCA2 mutations in a large United States sample. J Clin Oncol 2006;24(6):863-871.

8. Marroni F, Aretini P, D'Andrea E, et al. Penetrances of breast and ovarian cancer in a large series of families tested for BRCA1/2 mutations. Eur J Hum Genet 2004;12(11):899-906.

9. Metcalfe K, Lubinski J, Lynch HT, et al. Family history of cancer and cancer risks in women with BRCA1 or BRCA2 mutations. J Natl Cancer Inst 2010;102(24):1874-1878.

10. Graeser M, Engel C, Rhiem K, et al. Contralateral breast cancer risk in $B R C A 1$ and BRCA2 mutation carriers. J Clin Oncol 2009;27(35):5887-5892. 10.
11. Pierce LJ, Levin AM, Rebbeck TR, et al. Ten-year multi-institutional results of breast-conserving surgery and radiotheray in BRCA1/2-associated stage I/II breast cancer. J Clin Oncol 2006; 24(16):2437-2443

12. Eisinger F, Charafe-Jauffret E, Jacquemier J, Bimbaum D, Julian-Reynier C, Sobol H, et al. Tamoxifen and breast cancer risk in women harboring a BRCA1 germline mutation: computed efficacy, effectiveness and impact. Int J Oncol 2001;18(1):5-10.

13. Finch A, Beiner M, Lubinski J, et al. Salpingooophorectomy and the risk of ovarian, fallopian tube, and peritoneal cancers in women with a BRCA1 or BRCA2 mutation. JAMA 2006; 296(2):185-192.

14. Metcalfe KA, Birenbaum-Carmeli D, Lubinski J, et al. International variation in rates of uptake of preventive options in BRCA1 and BRCA2 mutation carriers. Int J Cancer 2008;122(9): 2017-2022.

15. Halbert $\mathrm{CH}$. Decisions and outcomes of genetic testing for inherited breast cancer risk. Ann Oncol 2004;15(1):35-39.

16. Ropka ME, Wenzel J, Phillips EK, Siadaty M, Philbrick JT. Uptake rates for breast cancer genetic testing: a systematic review. Cancer Epidemiol Biomarkers Prev 2006; 15(1):840-855.

17. Lazarus RS, Folkman S. Stress, Appraisal and Coping. Springer Publishing Company, Inc.: New York, NY, 1984.

18. Janis IL, Mann L, Decision Making. Free Press: New York, NY, 1977.

19. Rolland JS, Williams JK. Toward a biopsychosocial model for 21st century genetics. Fam Process 2005;44(1):3-24.

20. Cappelli MS, Surh L, Humphreys L, et al. Psychological and social determinants of women's decision to undergo genetic counseling and testing for breast cancer. Clin Genet 1999; 55(6):419-430.

21. Kelly K, Leventhal L, Andrykowski M, et al. The decision to test in women receiving genetic counseling for BRCA1 and BRCA2 mutations. J Genet Couns 2004; 13(3):237-257.

22. Blandy C, Chabal F, Stoppa-Lyonnet D, Julian-Reynier C. Testing participation in BRCA1/2-positive families: initiator role of index cases. Genet Test 2003;7(3):225-233.

23. Schwartz MD, Peshkin BN, Tercyak KP, Taylor KL, Valdimarsdottir H. Decision making and decision support for hereditary breastovarian cancer susceptibility. Health Psychol 2005;24(4S):S78-S84.

24. Gurmankin AD, Domchek S, Stopfer J, Fels C, Armstrong K. Patients' resistance to risk information in genetic counseling for BRCA1/2. Arch Intern Med 2005;165(Mar 14): 523-529.

25. Jacobsen PB, Valdimarsdottier HB, Brown KL Offit K. Decision-making about genetic testing among women at familial risk for breast cancer. Psychosom Med 1997;59:459-466.

26. Mellon S, Berry-Bobovski L, Gold R, Levin N, Tainsky MA. Communication and decisionmaking about seeking inherited cancer risk information: findings from female survivorrelative focus groups. Psycho-Oncology 2006;15(3):198-208.

27. Thompson HS, Valdimarsdottir HB, DuteauBuck C, et al. Psychosocial predictors of BRCA counseling and testing decisions among urban African-American women. Cancer Epidemiol Biomarkers Prev 2002, 11:1579-1585.

28. Hamilton RJ, Bowers BJ, Williams JK Disclosing genetic test results to family members. J Nurs Scholarsh 2005;37(1):18-24. 
29. Nycum G, Avard D, Knoppers BM. Factors influencing intrafamilial communication of hereditary breast and ovarian cancer genetic information. Eur J Hum Genet 2009; 17:872-880.

30. Seymour KC, Addington-Hall J, Lucassen AM, Foster CL. What facilitates or impedes family communication following genetic testing for cancer risk? A systematic review and meta-synthesis of primary qualitative research. J Genet Couns 2010;19:330-342.

31. DeMarco TA, McKinnon W. Life after BRCA1/2 testing: family communication and support issues. Breast Dis 2006-2007:127-136.

32. Ersig AL, Hadley DW, Koehly LM. Understanding patterns of health communication in families at risk for hereditary nonpolyposis colorectal cancer: examining the effect of conclusive versus indeterminate genetic test results. Health Commun 2011;26(7):587-594.

33. Koehly LM, Peterson SK, Watts BG, Kempf KK, Vernon SW, Gritz ER. A social network analysis of communication about hereditary nonpolyposis colorectal cancer genetic testing and family functioning. Cancer Epidemiol Biomarkers Prev 2003;12(4):304-313.

34. Speice J, McDaniel SH, Rowley PT, Loader S. Family issues in a psychoeducation group for women with a BRCA mutation. Clin Genet 2002;62(2):121-127.

35. Crotser CB, Boehmke M. Survivorship considerations in adults with hereditary breast and ovarian cancer syndrome: state of the science. J Cancer Surviv 2009;3:21-42.

36. Bieseker BB, Ishibe N, Hadley DW, et al. Psychosocial factors predicting BRCA1/BRCA2 testing decisions in members of hereditary breast and ovarian cancer families. Am J Med Genet 2000;93:257-263.

37. Claes E, Evers-Kiebooms G, Boogaerts A, Decruyenaere M, Denayer L, Legius E. Communication with close and distant relatives in the context of genetic testing for hereditary breast and ovarian cancer in cancer patients. Am J Med Genet 2003;116(A):11-19.

38. Hughes C, Lerman C, Schwartz M, et al. All in the family: Evaluation of the process and content of sisters' communication about BRCA1 and BRCA2 genetic test results. Am J Med Genet 2002;107(1):143-150.

39. Keenan LA, Lesniak KT, Guarnaccia CA, Althaus B, Ethington G, Blum JL. Family environments of women seeking BRCA1/ BRCA2 genetic mutation testing: an exploratory analysis. J Genet Couns 2004; 13(2): 157-176.

40. Landsbergen K, Verhaak C, Kraaimaat F, Hoogerbrugge N. Genetic uptake in BRCAmutation families is related to emotional and behavioral communication characteristics of index patients. Fam Cancer 2005;4(2):115-119.

41. Wolff LS, Subramanian SV, Acevedo-Garcia D, Weber D, Kawachi I. Compared to whom? Subjective social status, self-rated health, and referent group sensitivity in a diverse U.S. sample. Soc Sci Med 2010;70(12):2019-2028.

42. Katapodi MC, Aouizerat B. Do women in the community recognize hereditary and sporadic breast cancer risk factors? Oncol Nurs Forum 2005;32(3):617-623.

43. Wang C, Gonzalez R, Milliron KJ, Strecker VJ, Merajver SD. Genetic counseling for BRCA1/2: a randomized controlled trial of two strategies to facilitate the education and counseling process. Am J Med Genet 2005;134(A):66-73.

44. Moss-Morris R, Weinman J, Petrie K, Cameron L, Buick D. The revised Illness Perception Questionnaire (IPQ-R). Psychol Health 2002;17(1):1-16.

45. Katapodi MC, Dodd MJ, Facione NC, Humphreys JC, Lee KA. Why some women have an optimistic or a pessimistic bias about breast cancer risk: experiences, heuristics, and knowledge of risk factors. Cancer Nurs 2010;33(1):64-73.

46. Moos RH. Conceptual and empirical approaches to developing family-based assessment procedures: resolving the case of the Family Environment Scale. Fam Process 1990;29(1):199-208.

47. McCubbin HI, Thompson AI, McCubbin MA FPSC: family problem solving communication. In Family Assessment: Resiliency, Coping, and Adaptation, McCubbin HI, Thompson AI, McCubbin MA (eds). University of Wisconsin: Madison, WI, 1996;639-684.
48. McCubbin HI, Thompson AI, McCubbin MA (eds). FHI: Family Hardiness Index. Family assessment: Resiliency, Coping, and Adaptation. University of Wisconsin: Madison, WI, 1996;239-303.

49. Rubin DB, Schenker N. Multiple imputation in health-care databases: an overview and some applications. Stat Med 1991; 10(4):585-598.

50. Gaff CL, Collins V, Symes T, Halliday J. Facilitating family communication about predictive genetic testing: probands' perceptions. J Genet Couns 2005;14(2):133-140.

51. Anagnostopoulos F, Spanea E. Assessing illness representations of breast cancer: a comparison of patients with healthy and benign controls. J Psychosom Res 2005;58(1): 327-334.

52. Lerman C, Croyle RT, Tercyak KP, Hamann H. Genetic testing: psychological aspects and implications. J Consult Clin Psychol 2002; 70(3):784-797.

53. Hagger MS, Orbell S. A meta-analytic review of the common-sense model of illness representations. Psychol Health 2003;18(2): 141-184.

54. Cameron LD, Muller C. Psychosocial aspects of genetic testing. Curr Opin Psychiatry 2009;22(2):218-223.

55. McInerney-Leo A, Biesecker BB, Hadley DW, et al. BRCA1/2 testing in hereditary breast and ovarian cancer families II: impact on relationships. Am J Med Genet 2005;133A(2):165-169.

56. Mellon S, Janisse J, Gold R, et al. Predictors of decision making in families at risk for inherited breast/ovarian cancer. Health Psychol 2009;28(1):38-47.

57. Daly MB, Barsevick A, Miller SM, et al. Communicating genetic test results to the family: a six-step, skills-building strategy. Fam Community Health 2001;24(3):12-26.

58. McKinnon W, Naud S, Ashikaga T, Colletti R, Wood M. Results of an intervention for individuals and families with BRCA mutations: a model for providing medical updates and psychosocial support following genetic testing. J Genet Couns 2007;16(4): 433-456. 